\title{
A tsunami wave recorded near a glacier front
}

\author{
A. V. Marchenko ${ }^{1,2,3}$, E. G. Morozov ${ }^{4}$, and S. V. Muzylev ${ }^{4}$ \\ ${ }^{1}$ The University Center in Svalbard, Longyearbyen, Spitsbergen, Norway \\ ${ }^{2}$ Zubov State Oceanographic Institute, Moscow, Russia \\ ${ }^{3}$ Sustainable Arctic Marine and Coastal Technology (SAMCoT), Centre for Research-Based Innovation (CRI), Norway \\ ${ }^{4}$ Shirshov Institute of Oceanology, Russian Academy of Sciences, Moscow, Russia
}

Correspondence to: E. G. Morozov (egmorozov@mail.ru)

Received: 8 September 2011 - Revised: 10 December 2011 - Accepted: 12 December 2011 - Published: 27 February 2012

\begin{abstract}
We observed a tsunami wave near the glacier front in the Temple Fjord (Spitsbergen). Two temperature and pressure recorders were deployed on a wire from the ice approximately $300 \mathrm{~m}$ from the glacier front. A pressure recorder was located under them on the bottom. The vertical displacement of the ice was approximately $30 \mathrm{~cm}$ and the period of the tsunami wave was $90 \mathrm{~s}$. We attribute the generation of this wave to the displacement of the glacier similarly to the landslide tsunami generated by the motion of a block of rocks down the sloping bottom. The glacier motion also generated a short-period $(12 \mathrm{~s})$ deformation wave in the ice cover. The measurements allowed us to estimate the wave number of these waves and the Young's modulus of the ice.
\end{abstract}

\section{Introduction}

Landslide tsunamis are generated by the gravity flow of the materials on an inclined bottom. Usually, landslide tsunamis have smaller horizontal scales than tsunamis generated by earthquakes. They attenuate quickly due to the dispersion effects (Gonzalez and Kulikov, 1993). Theoretical investigations and laboratory modeling performed by Fine et al. (2003) indicate that submarine landslides are less effective at tsunami generation compared with subaerial slides. A rigidbody slide produces much higher tsunami waves than a viscous (liquid) slide. This result is confirmed in the review of tsunami mechanisms by Harbitz et al. (2006). Only a limited part of the potential energy released by the landslide is transferred to the wave energy. The critical parameter determining the generation of surface waves is the Froude number (the ratio between slide and wave speeds). The most efficient generation occurs near resonance when $F r=1.0$. Subaerial slides displace a considerable volume of water at relatively high speed as they slide into the water from the slope. One of the well known examples of subaerial landslides is the event in Nice on 16 October 1979, when a volume of ground slumped into the Mediterranean Sea during landfilling operations (Assier-Rzadkiewicz, 2000). Other examples are the landslide of 3 November 1994 in Skagway (Kulikov et al., 1996) during the collapse of a cruise ship wharf undergoing construction, and the underwater landslide of 17 July 1998 in Papua New Guinea caused by a moderate earthquake (Tappin et al., 1999). Recently, more articles have been published on tsunami generated by landslides, including subaerial ones (Fritz et al., 2009; Ranguelov et al., 2008; Vilibiæ et al., 2010).

Calving outflow glaciers produce big amounts of broken ice falling into the water. This effect can generate large water waves similarly to landslides. Sightseeing of calving glaciers is a very popular event in Polar tourist trips. Safety requirements setup that ships cannot approach the glacier wall closer than three heights of the glacier wall because broken ice can reach ship deck at close distances. Big water waves generated by calving glaciers can be dangerous for small boats, kayaks and tourist camps on the beach. There are no special requirements for the approaching outflow glacier in wintertime by sea ice, since the calving of glaciers is not as intense as in summer. Nevertheless, if it would happen, then the sea ice cover in the front of the glacier could be suddenly deformed and destroyed significantly. In this paper we consider a tsunami wave generated by the displacement of a glacier (Tunabreen) in the Temple Fjord (Spitsbergen) in February 2011. 


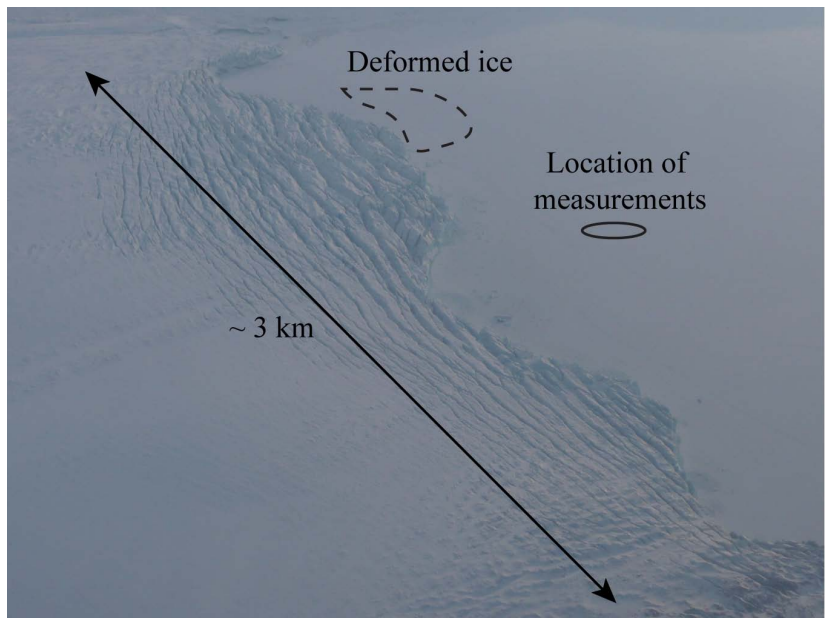

Fig. 1. The Tunabreen Glacier in the Temple Fjord in Spitsbergen (an aerial photo). The horizontal scales on the photo are distorted.

\section{Experiment}

Field works were performed on 16-19 February 2011 in the Temple Fjord in Spitsbergen near the glacier front. Two outflow glaciers, Tunabreen and Von-Postbreen, form the glacier front of about $3 \mathrm{~km}$ wide (Fig. 1). Although the glaciers have been stable since 2005, the visual observations show significant buckling deformations and folds of sea ice near the front of the Tunabreen (Fig. 2). The buckling deformations can be excited by the ice creep (Collins and McCrae, 1985). At the same time, ice compression can create sudden destruction of the ice due to the buckling instability (Sodhi et al., 1983).

The thickness of sea ice near the glacier was $94 \mathrm{~cm}$. Two SBE 39 temperature and pressure sensors were lowered from the ice covering the fjord at depths $z_{1} \approx 9.7 \mathrm{~m}$ and $z_{2} \approx 16.8 \mathrm{~m}$ at a distance of $\sim 300 \mathrm{~m}$ from the front of the Tunabreen (Figs. 1 and 3). The sampling time interval was $1 \mathrm{~s}$. An SBE 37 instrument with a sampling interval of $6 \mathrm{~s}$ was deployed at the bottom under them (Fig. 3).

The bottom gauge generally records the hydrostatic fluctuations of the water column (the frequency is of the order of $0.01 \mathrm{~Hz}$ and lower). The pressure gauges fixed on a wire from the ice surface do not record the hydrostatic fluctuations but record high frequency (of the order of $1 \mathrm{~Hz}$ ) non-hydrostatic vibrations of the ice cover.

The depth of the location was 46-48 m, depending on the tide phase. The height of the glacier over the ice cover was $40 \mathrm{~m}$. Then, on 17 February the instruments were recovered and one SBE 39 was lowered into the same hole in the ice together with the Aquadopp current meter. These instruments operated for one day.

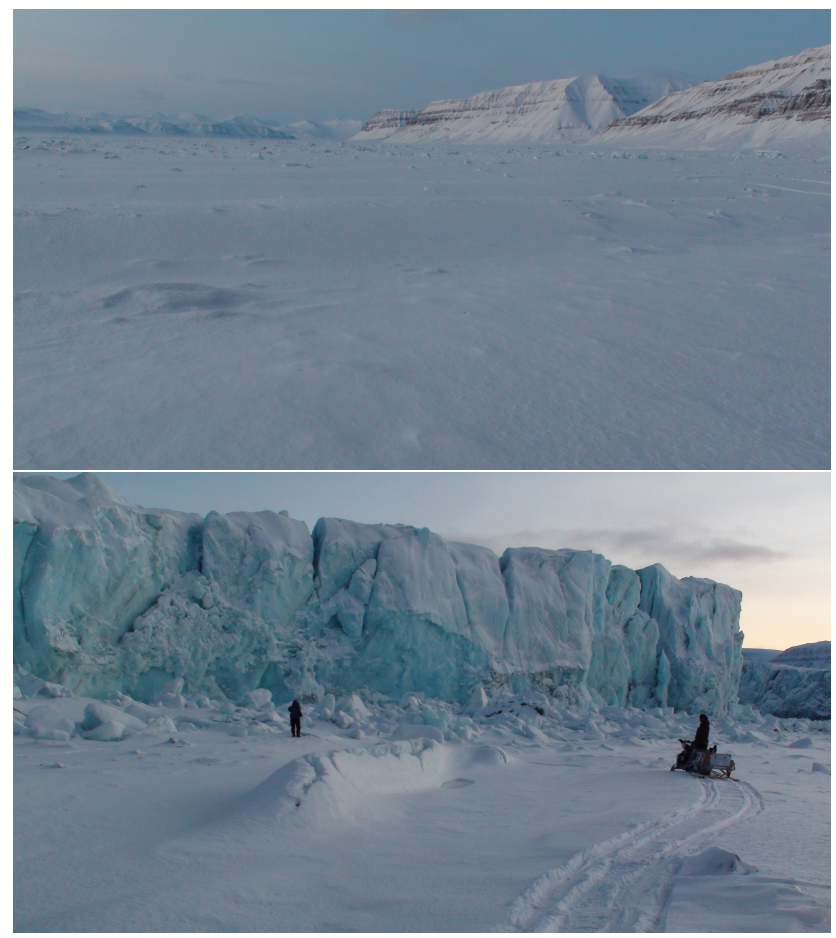

Fig. 2. Deformed sea ice near the glacier front: buckling (above) and fold (below)

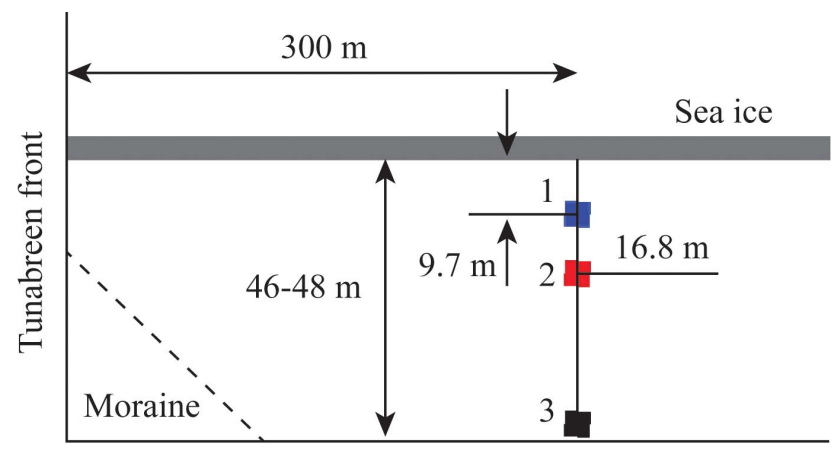

Sea bottom

Fig. 3. Scheme of the deployment of pressure recorders SBE 39 (1 and 2) and SBE-37 (3).

\section{Data records and analysis}

Approximately at 07:40 LT on 17 February, the instruments recorded a tsunami wave. A record of the pressure tide gauge at the bottom is shown in Fig. 4a. The time in hours from the beginning of the deployment is laid off as the abscissa. The tidal signal dominates in the record. A pressure perturbation is seen at the time period approximately corresponding to $80 \mathrm{~h}$. A detailed record of this pressure perturbation is shown in Fig. $4 \mathrm{~b}$. The zero time moment corresponds to $79.17 \mathrm{~h}$ after the deployment. We assume that this perturbation was 

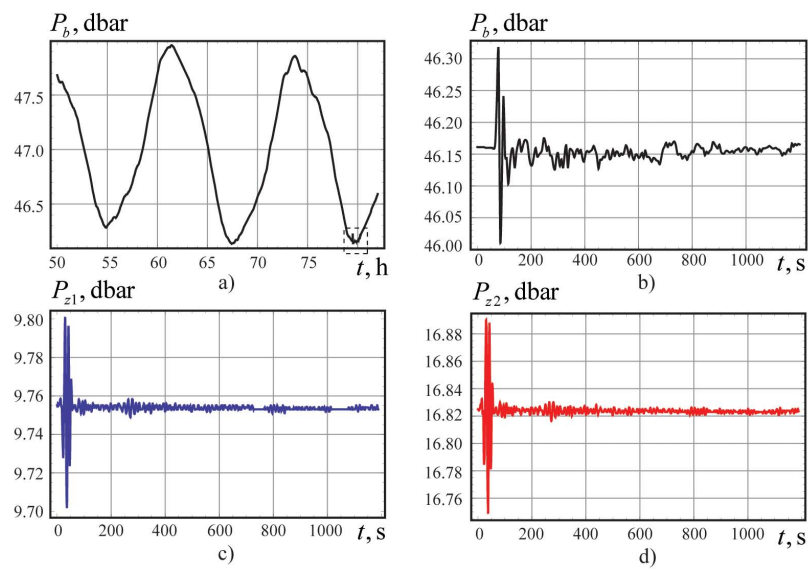

Fig. 4. Records of pressure gauges 3 (a, b), 1 (c) (blue curve), and 2 (d) (red curve). (b) shows in detail the perturbation indicated by a dashed line rectangle in (a).

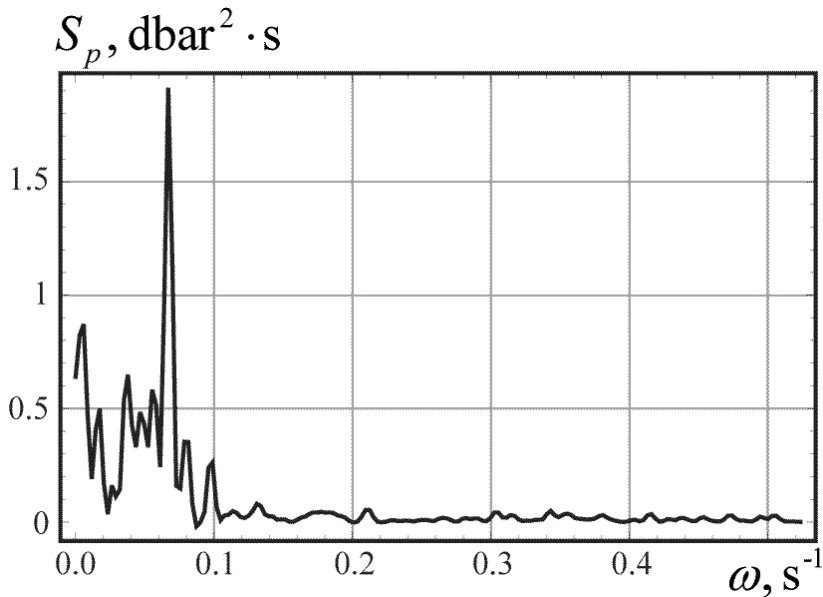

Fig. 5. Spectrum of the pressure gauge record at the bottom during the time interval of the tsunami event. The main peak corresponds to $93 \mathrm{~s}$.

caused by a tsunami wave. The time interval shown in detail in Fig. 4b is marked with a dashed line rectangle in Fig. 4a. It is seen from the figure that the leading pulse displaced the surface by more than $30 \mathrm{~cm}$. In the linear case, we associate the pressure perturbations as the elevations of the ice cover. It was followed by $10 \mathrm{~cm}$ fluctuations that later decreased to a few centimeters. It is worth noting that the event occurred at low tide, which seems to be a characteristic feature of landslides (Bjerrum, 1971; Johns, et al., 1986; Kulikov et al., 1996). Records of the pressure gauges 1 and 2 are shown in Fig. $4 \mathrm{c}$ and d, where the zero time moment is the same as in Fig. 4b. These records also include the leading pulse and the trailing wave tail.

The spectrum of the bottom pressure gauge reveals a peak of high confidence at a period of $93 \mathrm{~s}$. The spectrum is shown in Fig. 5. A landslide tsunami of a close period ( $2 \mathrm{~min})$ was
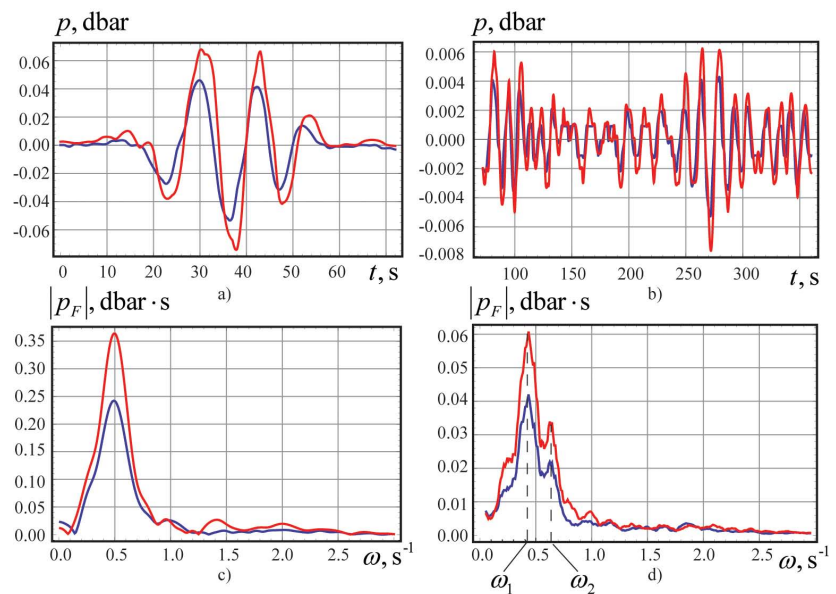

Fig. 6. Water pressure perturbations by the leading pulse (a) and wave tails (b) and absolute values of their Fourier transforms (c, d). Blue and red lines correspond to gauges 1 and 2, respectively.

reported in Rabinovich et al. (1999). We estimate the tsunami wave velocity as $c=\sqrt{g H}$, where $H$ is the water depth; then it is approximately equal to $20 \mathrm{~m} \mathrm{~s}^{-1}$ and the tsunami wave length over the depth of $46-48 \mathrm{~m}$ is approximately $1850 \mathrm{~m}$. Thus, we can use the shallow water approximation.

Not knowing that the instruments recorded a tsunami wave, we recovered them and replaced by one SBE-39 and Aquadopp current meter. The event recorded by the SBE-39 instrument on 19 February was weaker than the previous one. Again, the tsunami wave was recorded during the low water tide phase. The current meter recorded horizontal velocities of the water, the ice reaching $80 \mathrm{~cm} \mathrm{~s}^{-1}$.

The sampling frequency of gauge 3 at the bottom was not sufficient to resolve the high-frequency surface waves produced by the event. The waves are clearly seen in the detailed records. The leading signal and wave tails of water pressure perturbations created by the event are shown in Fig. 6a and b by blue lines for gauge 1 and red lines for gauge 2 . The Fourier transforms of the first signals and wave tails were calculated from the relation

$p_{\mathrm{F}}=\frac{1}{\sqrt{2 \pi}} \int_{-\infty}^{\infty} p e^{i \omega t} \mathrm{~d} t$.

The Fourier transforms are shown in Fig. $6 c$ and d with blue lines for gauge 1 and red lines for gauge 2. One can see that the leading signals of both gauges have spectral maxima at a frequency of $\omega_{0} \approx 0.5 \mathrm{~s}^{-1}$. Wave tails in the records of both gauges have two spectral maxima at frequencies $\omega_{1} \approx 0.435 \mathrm{~s}^{-1}$ and $\omega_{2} \approx 0.625 \mathrm{~s}^{-1}$.

In the linear theory of surface periodical waves perturbations of water pressure at depth $z$ are described by the following formula (Mei, 1983) 
$p_{z}=\rho_{\mathrm{w}} a\left(\frac{\omega^{2} \cosh k(z+H)}{k \sinh k H}-g\right) \cos (k x-\omega t)$,

where $a, \omega$ and $k$ are the wave amplitude, frequency, and wave number, respectively; $H$ and $\rho_{\mathrm{w}}$ are the water depth and density, and $g$ is the gravity acceleration. In the homogeneous water covered by an elastic plate, the wave frequency is related to the wave number by the dispersion equation (Marchenko et al., 2010; Squire et al., 1996)

$\omega^{2}=k \tanh k H\left(g+D k^{4}\right), \quad D=\frac{E h^{3}}{12 \rho_{\mathrm{W}}\left(1-v^{2}\right)}$,

where $E$ and $v$ are the Young's modulus and Poisson ratio of the ice, and $h$ is the ice thickness. The ratio of the water pressures at depths $z_{1}$ and $z_{2}$ is determined as follows

$\Delta_{12}=\frac{p_{z 1}}{p_{z 2}}=\frac{\omega^{2} \cosh k\left(z_{1}+H\right)-g k \sinh k H}{\omega^{2} \cosh k\left(z_{2}+H\right)-g k \sinh k H}$.

Equation (4) can be used for the calculation of wave number $k$ when perturbations of the water pressures at two depths $\delta p_{z 1}$ and $\delta p_{z 2}$ are known. Then the dispersion equation is used for the calculation of the ice rigidity $D$. Since the ice thickness $h=0.94 \mathrm{~m}$ was measured and the Poisson ratio of ice $v \approx 0.34$ is very stable, the dispersion relation can be used for the estimates of the Young's modulus $E$ of the ice.

Ratio $\Delta_{12}$ is estimated as a ratio of the Fourier transform maxima at frequencies $\omega_{1}$ and $\omega_{2}$. It results in wave numbers $k_{1}=0.0246 \mathrm{~m}^{-1}$ and $k_{2}=0.0405 \mathrm{~m}^{-1}$, respectively. The wave lengths are equal to $255.4 \mathrm{~m}$ and $155.1 \mathrm{~m}$. The amplitude of the wave tail shown in Fig. $5 \mathrm{~b}$ and estimated by formula (2) is smaller $(2.2 \mathrm{~cm})$. It corresponds to the amplitude of the wave tail recorded by gauge 3 at the bottom. The estimate of the Young's modulus performed for the shortest wave with frequency $\omega_{2}$ gives a value of $E=1.7 \mathrm{GPa}$. It is a low boundary of the range $1.7-9.1 \mathrm{GPa}$ of many measurements of the Young's modulus performed in smaller scales by mechanical and acoustic methods (Bogorodskii and Gavrilo, 1980; Weeks and Assur, 1986; Vagapov et al., 1993).

\section{Conclusions}

The measurements of the pressure at the bottom near the glacier front in the Temple Fjord (Spitsbergen) allowed us to record a tsunami wave. The recording instruments (two temperature and pressure recorders) at depths of 9 and $16 \mathrm{~m}$ and a pressure gauge at the bottom at $46 \mathrm{~m}$ were deployed at a distance of approximately $300 \mathrm{~m}$ from the glacier front. The displacement of the glacier front, landslide of the moraine near the glacier front, and buckling instability of the compressed ice can be the causes of wave generation. The vertical displacement of the ice by the leading pulse was approximately $30 \mathrm{~cm}$, the period of the tsunami wave was $90 \mathrm{~s}$ and the wave length was $1850 \mathrm{~m}$. We interpret the records as the tsunami wave generation during the low tide phase caused by the displacement of the glacier or probably a landslide of the moraine, similarly to the landslide tsunami generated by the motion of a block of rocks down the sloping bottom. We consider that this was a glacier motion without ice fall, as no new fallen ice blocks were found, but the ice cover was deformed.

The glacier motion also generated short-period (10 s and $14.4 \mathrm{~s}$ ) deformation waves in the ice cover with wavelengths of 150 and $250 \mathrm{~m}$. The response of the water column was strongly non-hydrostatic, which allowed the pressure gauges hanging on a wire to record this signal. The duration of the leading signal was about $40 \mathrm{~s}$. Then, the trailing wave tail was recorded during approximately $20 \mathrm{~min}$. The wave amplitude in the tail reached $2.2 \mathrm{~cm}$ during first $5 \mathrm{~min}$ of the event and then it dropped gradually to zero with insignificant modulations of the wave amplitude. The wave tail is probably formed due to the reflection of the leading signal from the coast of the fjord. The pressure measurements at two depths allowed us to estimate the wave number of these waves and the Young's modulus of the ice $(E=1.7 \mathrm{GPa})$, which is at the low boundary of the measurements based on other methods (1.7-9.1 GPa).

The Temple fjord region is a frequently visited place by tourists driving the snow-scooters. Environmental tourism in this fjord is subjected to strong influence of storms in the ocean. In March of 2010, the $50 \mathrm{~cm}$ thick ice cover was partly destroyed by the storm (wind and waves from the ocean). A similar event, when the winter storm in the Baltic Sea destroyed an ice-cover, is also described by Orviku et al. (2009). In addition, a strong motion of the glacier can generate a stronger tsunami wave than we measured, which may also lead to the breaking of the ice cover in the fjord. From this perspective, the high water phase of the tide is the most favorable and safe time of approaching the glacier.

Acknowledgements. This research was supported by the Norwegian Research Council through the POLRES project (196138) and the Centre for Sustainable Arctic Marine and Coastal Technology (SAMCoT). The work was also supported by the RussianFoundation for Basic Research (projects nos. 11-08-00076, 11-05-00448, 10-08-01010, and 09-05-00599.

Edited by: I. Didenkulova

Reviewed by: C. W. Finkl, B. Ranguelov, and another anonymous referee

\section{References}

Assier-Rzadkiewicz, S., Heinrich, P., Sabatier, P. C., Savoye, B., and Bourillet, J. F.: Numerical modelling of a landslidegenerated tsunami: The 1979 Nice event, Pure Appl. Geophys., 157, 1707-1727, 2000.

Bjerrum, L.: Sub-aqueous slope failures in Norwegian fjords, Oslo: Norw. Geotech. Inst., 88, 8 pp., 1971. 
Bogorodskii, V. V. and Gavrilo, V. P.: Ice, physical properties, Modern methods of glaciology, Leningrad, Gidrometeoizdat, 384 pp., 1980 (in Russian).

Collins, I. F. and McCrae, I. R.: Creep buckling of ice shelves and the formation of pressure rollers, J. Glaciol., 31, 242-252, 1985.

Fine, I. V., Rabinovich, A. B., Thomson, R. E., and Kulikov, E. A.: Numerical modeling of tsunami generation by submarine and subaerial landslides, Submarine Landslides and Tsunamis, edited by: Yalciner, A. C., Pelinovsky, E., Synolakis, C. E., and Okal, E., Kluwer Academic Publishers, 73-93, 2003.

Fritz, H. M., Mohammed, F., and Yoo, J.: Lituya Bay landslide impact generated mega-tsunami 50(th) anniversary, Pure Appl. Geophys., 166, 153-175, 2009.

Gonzalez, F. I. and Kulikov, Ye. A.: Tsunami dispersion observed in the deep ocean, in Tsunamis in the World, edited by: Tinti, S., Kluwer Acad., Norwell, Mass., 7-16, 1993.

Harbitz, C. B., Løvholt, F., Pedersen, G., and Masson, D. G.: Mechanisms of tsunami generation by submarine landslides: a short review, Norwegian J. Geol., 86, 255-264, 2006.

Johns, M. W., Prior, D. B., Bornhold, B. D., Coleman, J. M., and Bryant, W. R.: Geotechnical aspects of a submarine slope failure, Kitimat Fjord, British Columbia, Mar. Geotechnol., 6, 243-279, 1986.

Kulikov, E. A., Rabinovich, A. B., Thomson, R .E., and Bornhold, B. D.: The landslide tsunami of November 3, 1994, Skagway Harbor, Alaska, J. Geophys. Res., 101, 6609-6615, 1996.

Marchenko, A. V., Morozov, E. G., Muzylev, S. V., and Shestov, A. S.: Interaction of Short Internal Waves with the Ice Cover in an Arctic Fjord, Oceanology, 50, 18-27, 2010.

Mei, C. C.: The Applied dynamics of ocean surface waves, Wiley, New York, 740 pp., 1983.

Orviku, K., Suursaar, Ue., Tonisson, H., Kullas, T., Rivis, R., and Kont, A.: Coastal changes in Saaremaa Island, Estonia, caused by winter storms in 1999, 2001, 2005 and 2007, J. Coast. Res.h, 56, 1651-1655, 2009.
Rabinovich, A. B., Thomson, R. E., Kulikov, E. A., Bornholf, B. D., and Fine, I. V.: The landslide-generated tsunami of November 3, 1994 in Skagway Harbor, Alaska: A case study, Geophys. Res. Lett., 26, 3009-3012, 1999.

Ranguelov, B., Tinti, S., Pagnoni, G., Tonini, R., Zaniboni, F., and Armigliato, A.: The nonseismic tsunami observed in the Bulgarian Black Sea on May, 7th 2007. Was it due to a submarine landslide?, Geophys. Res. Lett., 35, L18613, doi:10.1029/2008GL034905, 2008.

Sodhi, D. S., Haynes, F. D., Kato, K., and Hirayama, K.: Experimental determination of the buckling loads of floating ice sheet, Ann. Glaciol., 4, 260-265, 1983.

Squire, V. A., Hosking, J. R., Kerr, A. D., and Langhorne, P. J.: Moving loads on ice plates, Kluwer Academic Publishers, 230 pp., 1996.

Tappin, D.R., Matsumoto, T., Watts, P., Satake, K., McMurtry, G. M., Matsuyama, M., Lafoy, Y., Tsuji, Y., Kanamatsu, T., Lus, W., Iwabachi, Y., Yeh, H., Matsumoto, Y., Nakamura, M., Moihoi, M., Hill, P., Crook, K., Anton, L., and Walsh, J. P.: Sediment slump likely caused 1998 Papua New Guinea tsunami, EOS, 80, 329-334, 1999.

Vagapov, R. H., Gavrilo, V. P., Kozlov, A. I., Lebedev, G. A., and Logvin, A. I.: Remote methods of sea ice research. St.Petersburg, Gidrometeoizdat, 343 pp., 1993.

Vilibiæ, Iv., Šepiæ, J., Ranguelov, B., Mahoviæ, N. S., and Tinti, S.: Possible atmospheric origin of the 7th May 2007 western Black Sea shelf tsunami event, J. Geophys. Res., V 115, C07006, doi:10.1029/2009JC005904, 2010.

Weeks, W. F. and Assur, A.: The mechanical properties of the sea ice. Proc. of Conf. on the Ice Pressure Against Structure, Loaval Univ., Quebec, Canada, 1986. 